\title{
A Tradição Luterana e Comunitária nas Escolas da IECLB: Aproximações com os Ideais de Democratização da Educação
}

\author{
Sandra Vidal Nogueira ${ }^{1}$
}

\section{RESUMO}

O texto aborda a tradição luterana e comunitária nas escolas da Igreja Evangélica de Confissão Luterana no Brasil (IECLB), destacando a Reforma Protestante para os ideais de democratização da educação. Parte-se do pressuposto que essas comunidades, cuja membresia é, por razões histórias, delineada a partir da etnia, têm contribuído sobremaneira para o incremento da educação, principalmente no Sul do Brasil. Entendida num sentido mais amplo, o conceito de educação que subjaz ao ideário luterano possibilita o domínio e a compreensão da "palavra" e a sua prática cria condições para "o livre libertado", nas palavras de Martinho Lutero. Em síntese, consta-se que o grande desafio enfrentado na contemporaneidade consiste em buscar a centralidade dos ideais da Reforma que foi sendo construído, alicerçado nas seguintes diretrizes pedagógicas: 1) Reciprocidade e interação entre escola e comunidade; 2) Liberdade de expressão, autonomia de pensamento e igualdade de oportunidades; 3) Desenvolvimento integral do ser humano.

1 Doutora em educação pela PUC/SP. Servidora Pública Federal integrante da Carreira do Magistério Superior na Universidade Federal da Fronteira Sul, Campus Cerro Largo, RS. 
PALAVRAS-CHAVES

Luteranismo; Imigração Alemã; Educação comunitária.

\begin{abstract}
The text covers the Lutheran tradition and community schools the Evangelical Church of Lutheran Confession in Brazil (IECLB), highlighting the Protestant Reformation to the ideals of democratization of education. This is on the assumption that those communities whose membership is by stories reasons outlined from the ethnic group, have contributed greatly to the growth of education, especially in southern Brazil. Understood in a broader sense, the concept of education that underlies the ideology Lutheran enables mastery and understanding of the "word" and its practice creates conditions for "free released" in the words of Martin Luther. In summary, it stated that the major challenge facing nowadays is to seek the centrality of the ideals of the Reformation that was being built, based on the following educational guidelines: 1) Reciprocity and interaction between school and community; 2) Freedom of expression, freedom of thought and equal opportunities; 3 ) full development of the human being.
\end{abstract}

\title{
KEYWORDS
}

Lutheranism; German Immigration; Community Education.

\section{Considerações iniciais}

Desde 1824 os imigrantes alemães se fazem presentes em terras brasileiras, por meio da criação de núcleos coloniais, inicilamente, em São Leopoldo, RS e Nova Friburgo, $\mathrm{RJ}^{2}$. Favorecidos pelas políticas migratórias, a vinda dessas pessoas para o país acontece a partir de um processo

2 Segundo Martin N. Dreher, História do Povo Luterano. São Leopoldo: Sinodal, 2005, p. 51: "Os imigrantes foram assentados principalmente nas três províncias meridionais do Brasil: Rio Grande do Sul, Santa Catarina e Paraná, mas houve assentamento considerável no Espírito Santo. Grupos menores foram estabelecidos em São Paulo, Rio de Janeiro e Minas Gerais (...) as primeiras comunidades: Nova Friburgo (1824), São Leopoldo (1824), Três Forquilhas (1826)". 
que tem em sua gênese em motivações mais de natureza econômica e política do que propriamente baseadas em questões de ordem religiosa. Nesse sentido, pode-se afirmar, segundo Dreher, que "a instalação do luteranismo no Brasil não ocorreu em virtude de atividades de sociedades missionárias luteranas, mas como consequência das necessidades do ser humano migrante" 3 .

A saída, em massa, da Europa aconteceu em decorrência de uma confluência de fatores, a saber: o êxodo rural, as tentativas de reformas agrárias, a industrialização, o crescimento dos centros urbanos e o colapso da agricultura, fruto da importação de produtos a baixos custos. De acordo com Dreher ${ }^{4}$,

De 1800 a 1845 saíram da Europa 1.5milhões de pessoas. Já entre 1845 e 1875, foram 9.5 milhões. A partir de 1880, essas cifras passam a ser de cerca de 800 mil pessoas ao ano, explodindo desde 1900, quando 1.4 milhões deixaram anualmente o continente europeu.

Segundo Altmann e Dreher ${ }^{5}$, a preocupação com a educação, já identificada por Martinho Lutero, extrapola os limites do espaço privado, no âmbito da casa e da família e aparece de forma marcante na vida pública, na imagem da tríade: igreja-escola-cemitério, cujos reflexos se fazem sentir até hoje no cotidiano das cidades originárias da colonização alemã. Não se pode esquecer contudo, que em terras brasileiras esses imigrantes não tiveram o apoio do Estado:

No todo, porém, vale para os primeiros quarenta anos de história das comunidades evangélicas, que mais tarde viriam a formar a Igreja Evangélica de Confissão Luterana no Brasil, que estavam entregues a si mesmas, ou melhor, à graça de Deus ${ }^{6}$.

3 DREHER, 2005, p. 51.

4 DREHER, 2005, p. 49.

5 ALTMANN, Friedhold. A roda: memórias de um professor. São Leopoldo: Sinodal, 1991; DREHER, M. N. Breve história do ensino privado gaúcho. 01. ed. São Leopoldo/RS: Oikos, 2008.

6 DREHER, 2005, p. 52. 
Neste cenário, nasce, cresce e se consolida a tradição comunitária alicerçada na herança luterana ${ }^{7}$. Ou seja, as comunidades luteranas, cuja membresia é, por razões histórias, em sua maioria rural e campesina, por meio das instituições por elas criadas, têm contribuído sobremaneira para o incremento de políticas, programas e projetos de educação numa perspectiva democrática, em especial na Região Sul do Brasil, através do diálogo crítico estabelecido nas escolas comunitárias criadas nas linhas, picadas, vilas e cidades das diferentes regiões colonizadas ${ }^{8}$.

Apesar da importância da Reforma Protestante ${ }^{9}$ na difusão dos ideais de democratização da sociedade e seu legado, constituir as bases sobre o direito à educação ${ }^{10}$, é possível constatar que ainda são exíguos os estudos que tratam desse assunto no contexto educacional brasileiro. Portanto, priorizou-se na redação deste Artigo, alguns vetores iniciais de acesso ao estudo sobre historiografia da Igreja Evangélica de Confissão Luterana no Brasil (IECLB) ${ }^{11}$.

7 De acordo com Boaventura de Sousa Santos. A crítica da razão indolente: contra o desperdício da experiência (São Paulo: Cortez, 2000), p. 75, o princípio da comunidade é "o mais bem colocado para instaurar uma dialética positiva com o pilar da emancipação”.

8 Para maiores esclarecimentos consultar: Leonard (1963); Kreust, (1994); Grutzmann, Dreher e Feldens (2008), Wachs; Goldmeyer e Malschitxky (2006) e Nogueira e Rodrigues (2007).

9 O que se designa de "Reforma Protestante" integra um conjunto histórico de crise e renovação do cristianismo ocidental, abarcando os séculos XV e XVI. As primeiras tentativas de reforma vão ser feitas na Espanha por Isabel, a Católica e por seu confessor, o Cardeal Ximenez de Cisnero, seguidas, ainda, na Alemanha (Lutero), Zurique/ Suíça (Zwínglio e os anabatistas), Genebra/Suíça (Calvino), nos Países Baixos e na França (reformados) e no Concílio de Trento sob a liderança da Companhia de Jesus. De maneira sucinta, pode-se dizer, que a Reforma Protestante se constituiu num decidido esforço por restituir a integridade da Igreja, em consonância com a redescoberta do Evangelho da graça divina, acessível a todos mediante a fé, contra os abusos que eram praticados, por exemplo, no comércio de indulgências. Na atualidade, acoplado aos esforços ecumênicos, o legado da Reforma à cristandade diz respeito a busca perseverante da integridade da Igreja, em consonância com a Escritura, como sendo fonte normativa da fé (ALTMANN, 1994 e 2001; LUTERO, 2000; WEBER, 1999).

${ }_{10}$ Para maiores esclarecimentos consultar: Alves (1979), Dreher (1988), Toledo (1999) e Barbosa (2007).

${ }^{11}$ A IECLB é forte atuante na área diaconal, atividades ecumênicas e missões evangelísticas. A igreja organiza-se em comunidades, paróquias e sínodos. Os laços de comunhão confessional essencialmente vinculadosao empenho ecumênico da IECLB 


\section{O papel da formação nas escolas comunitárias}

A historiografia existente sobre a IECLB centra-se no aprofundamento de estudos e investigações sobre a dimensão institucional de constituição das igrejas e comunidades. Aliás, não se pode esquecer: a própria constituição da IELCB acontece no Brasil de maneira gradual, a partir da organização das diferentes comunidades em sínodos e destes numa Igreja de abrangência nacional, somente no ano de 1968. Para Dreher, a luta pelos ideais de liberdade

(...) tem sua razão de ser e está relacionada a situações que haviam enfrentado na Pomerânia, território que pertencia à Prússia e que hoje faz parte da Polônia. Ali, a maior parte dos imigrantes havia estado na condição de servos da gleba. Eram escravos. O pastor e a igreja territorial representavam o latifundiário e o Estado e tinham função de polícia. Submeter-se, no Brasil, novamente a uma organização social seria voltar à antigacondição ${ }^{12}$.

Sobre o lento processo de unificação das igrejas e da formação da IECLB, escreveu Streck ${ }^{13}$,

há no movimento da Reforma alguns impulsos que continuam muito atuais e podem contribuir para orientar a educação na Igreja e na sociedade. Destaco o princípio do sacerdócio universal de todos os crentes, a defesa da liberdade radical do cristão e a centralidade da cruz como sinalizadora do caminho do cristão.

foram tradicionalmente com igrejas evangélicas na Alemanha (atualmente inseridos na vida da Federação Luterana Mundial - FLM como comunhão luterana em nível global). Estas comunidades começaram a organizar-se no Brasil com apoio da Igreja Territorial da Alemanha. Em 1886, fundou-se o Sínodo Rio-Grandense da Igreja Evangélica Alemã. Em 1968, esse Sínodo, com o Sínodo Protestante Luterano de Santa Catarina, Paraná e outros Estados da América do Sul (1905), a Associação de Comunidades Protestantes de Santa Catarina e Paraná (1911) e o Sínodo Evangélico do Brasil Central, formaram a Igreja Evangélica de Confissão Luterana no Brasil (IECLB).

12 DREHER, 2005, p. 54.

13 STRECK, Danilo Romeu (org.). Educação e Igrejas no Brasil: um ensaio ecumênico. São Leopoldo: CELADEC, 1995, p. 32. 
Vale lembrar, de acordo com Baeske ${ }^{14}$, citando as obras de Lutero e Marx, que "Não admira que Karl Marx em 'O Capital' cite, como único teólogo, Lutero, e os marxistas contemporâneos chegam a fazer descobertas nele que deixam muita 'gente luterana' perplexa".

Desde a década de 70, pode ser constatada, nos debates eclesiásticos, uma forte ênfase na missão da igreja de confissão luterana no território brasileiro. Destaca-se, nesse contexto, a transferência da V Assembléia Geral da Federação Luterana Mundial (1970), que tinha como tema geral "Enviados ao Mundo", seis semanas antes de sua realização, de Porto Alegre, no Brasil, para Evian, na França, em virtude da situação política vigente no país, do reconhecimento internacional da violação dos direitos humanos no Brasil e também pelos crescentes questionamentos acerca da ação missionária do luteranismo no context mundial ${ }^{15}$. Segundo Muller ${ }^{16}$,

As igrejas luteranas - as que se fizeram presentes em Evian descobriram junto ao Lago de Genebra o mundo injusto e anti-social do ano de 1970, sua ameaça para os seres humanos e para a vida. Para esta descoberta puseram muita coisa em risco: sua unidade a unanimidade de suas manifestações, um cancelamento que podia ser interpretado como fuga, uma controvérsia que poderia ter levado à cisão a própria Federação Mundial, e o conflitopermanente.

E, acrescenta o autor:

${ }^{14}$ BAESKE, Albérico. Educação para a liberdade: uma visão luterana. In: Estudos Teológicos. São Leopoldo: Sinodal, ano 25, nº1, 1985, p. 8.

${ }^{15}$ Naquele período histórico, marcado fortemente, no plano político, pela ditadura militar, desde 1964, deacordo com Dreher (2005, p. 59), “já se encontrava pronta a redação do documento que, em outubro de 1970, seria aceito pelo Concílio Geral da Igreja, passando a ser reconhecido sob o nome de 'Manifesto de Curitiba'(...) o documento, que se reporta a Ezequiel 33.7 (...) afirma que a igreja deve 'desempenhar uma funçãocrítica - não de fiscal, mas antes de vigia e de consciência da Nação (...) A partir de então ospronunciamentos são constantes: solicitação de anistia, protestos pelo sofrimento de colonos afetados pelaconstrução de barragens, discussão com a Fundação Nacional do Índio (FUNAI), exigência de aplicação doEstatuto da Terra e da reforma agrária."

${ }^{16}$ MÜLLER, Reinhart. A transferência da V Assembléia geral da Federação Luterana Mundial de Porto Alegre para Evian/França. In: FISCHER, Joaquim. Ensaios luteranos: dos primórdios aos tempos atuais do luteranismo no Brasil. Trad. Walter O Schlupp. São Leopoldo: Sinodal, 1986, p. 126. 
Com certeza o ano de 1970 permanece significativo dentro da história da Federação Mundial também pelo seguinte: As igrejas luteranas, este verão, não estiveram em condições de expressar de forma clara, convincente e unida o quer dizer: 'enviados ao mundo'; nem de responder ás perguntas: Quem envia? Quem é enviado? Com que evangelho? O processo de recepção crítica exige a continuação dos trabalhos nas seguintes direções:

1. Como fornecer a informação necessária para ver, julgar e agir de forma conjunta? 2. Como constatar e manter a unidade face a julgamentos divergentes e decisões políticas contrárias? 3. Como pôr em prática a parceria entre igrejas dentro das condições vigentes nas igrejas e sociedades? (p.127)

Concluída na França, em 24 de julho de 1970, a V Assembléia Geral da Federação Luterana Mundial, caracterizou a pessoa humana como tema principal da teologia. Para Muller (1986, p.126), esta-se falando

não da pessoa humana como membro da igreja, como cristão efetivo ou em potencial, mas como membro de uma humanidade que se configura em coletivos não-eclesiais; em sociedade e classes, sob condições de dominação e dependência econômica, social e política.

Outros importantes indicadores que extrapolam o âmbito eclesiástico e abordam questões de natureza política foram produzidos nesse período como um guia de ação diaconal, denominado de "Nossa Responsabilidade Social" e um programa missionário que originou a elaboração de um documento, sob o mesmo nome, "Catecumenato Permanente Discipulado Permanente”, aprovado pelo IX Concílio Geral, realizado em Cachoeira do Sul/RS, em 1974, tendo ainda a proposição de criação de um centro de elaboração de material para subsidiá-lo. Dentre as principais teses defendidas no referido Documento podem ser destacados os seguintes propósitos básicos: a) a busca por uma teologia e umaprática educativa mais contextualizada; b) a aproximação da teologia com as reflexões pedagógicas; c) a valorização do ministério educacional ${ }^{17}$.

17 Desde 1994 são oficialmente reconhecidos pela IECLB três ministérios ordenados e formados pela Escola Superior de Teologia: o pastoral, o catequético e o diaconal. 
Em face das profundas mudanças na realidade política e social que aflige a humanidade na contemporaneidade, a missão educativa da Igreja é questionada, também, no que diz respeito aos processos de evangelização permanente, dando origem aos movimentos e grupos na educação comunitária ${ }^{18}$. Dentre eles merecem destaque: a Pastoral Popular Luterana (PPL); o Movimento Encontrão; o Movimento Carismático e a Missão Evangélica União Cristã (MEUC).

Existem, ainda, outros organismos que têm na educação dos membros das comunidades uma de suas funções principais: a Ordem Auxiliadora de Senhoras Evangélicas (OASE), o Departamento de Juventude e o Departamento de Catequese. Há de se ressaltar, segundo Dreher ${ }^{19}$, que na IECLB "coexistem diferentes formas de evangelização e nelas se expressam diversas tendências do ser cristão, que refletem também os diferentes contextos em que vivem cristãos".

Entendida num sentido mais amplo, a educação possibilita, em essência, o domínio e a compreensão da "palavra" e a sua prática cria condições para "o livre libertado", nas palavras de Martin Lutero. Sobre este assunto, o Pastor Hermann G. Dohms (1946, p.16-17) defende a seguinte tese: analfabetismo significa muito mais do que não saber ler ou escrever, mas a falta de desenvolvimento das faculdades intelectuais, da faculdade de falar, de formar juízo moral ou assinalar idéias distintas, de, em suma, entrar em contato com uma comunhão espiritual.

Por todo esse context histórico, via de regra, as escolas comunitárias luteranas trazem em sua trajetória uma postura de idoneidade e um sólido compromisso com o desenvolvimento integral do ser humano capaz de dar conta dos problemas, bem como com as inovações e melhorias organizacionais, em suas várias dimensões, procurando adequar-se constantemente às transformações sociais e influir nas mudanças pelas quais tem passado o sistema de gestão acadêmica e administrativa das

\footnotetext{
${ }^{18}$ LOURO, Guacira Lopes. História, Educação e Sociedade no Rio Grande do Sul. Porto Alegre: Educação e Realidade Edições, 1986; DREHER, Martin N. A igreja latino-americana no contexto mundial. São Leopoldo: Sinodal, 1999.

${ }^{19}$ DREHER, 2005, p. 62.
} 
instituições educacionais, nos contextos específicos da educação básica e do ensino superior no Brasil ${ }^{20}$. Não é por acaso que, segundo Streck ${ }^{21}$, "em 1934 existiam 513 escolas com 589 professores e 17.177 alunos". Embora esses números tenham obtido um decréscimo significativo

Até o momento há dúvida sobre o número de escolas étnicas no Brasil. Este varia de acordo com as fontes. A divergência, quanto aos números, deve-se em parte ao período de tensões fortes entre governo e lideranças destas escolas, de 1938 a 1941 (...) Hoje, estima-se que tenham sido em torno de 2500. O maior número de escolas étnicas foi dos imigrantes alemães, com 1579 escolas, seguindo-se as dos italianos com 396, dos poloneses com 349 e dos japoneses com $178^{22}$.

Permanece forte, contudo, um determinado padrão institucional organizativo, que atrela a idéia da escola comunitária à imagem da paróquia. De igual maneira, se fazem presentes as marcas históricas de uma igreja delineada a partir da etnia, ou seja, segundo Dreher, "de uma identidade que esteve mais orientada para a germanidade do que para o luteranismo" 23.

Esse crescimento, por sua vez, revelou a existência de duas necessidades prementes. A primeira, a de uma formação de professores e

${ }^{20}$ O Sínodo Riograndense criou, em 1924, por ocasião do centenário da imigração alemã no Sul do Brasil, seu Departamento de Ensino. O Conselho Sinodal de Educação, órgão criado em 1964 para coordenar o "Sistema Sinodal de Educação", funcionou até 1969. Com a criação, em 1968, da IECLB - Igreja Evangélica de Confissão Luterana no Brasil - ele se extinguiu. Em 1981 ocorreu a reestruturação - em vigor até os dias atuais. O Centro de Diretores de Escolas Evangélicas transformou-se na Associação Evangélica de Educação. Foi novamente instituído o Conselho de Educação e instalada uma Direção Executiva, em substituição à Secretaria Executiva do CDEE e ao Departamento de Ensino. Esses três órgãos passaram a integrar o Departamento de Educação - IECLB. No ano 2000, o Departamento é renomeado para sua atual denominação: Rede Sinodal de Educação. A Rede Sinodal de Educação é, assim, o órgão responsável, na IECLB, pelo setor educacional escolar e universitário, prestando serviço às escolas vinculadas com Comunidades ou Paróquias Evangélicas. Ela é integrada por todas as 51 escolas (distribuídas em cinco estados do país) filiadas e sua Assembléia Geral é o foro máximo de deliberação.

${ }^{21}$ STRECK, Gisela I.W. Escola comunitária: fundamentos e identidade. São Leopoldo: Editora Sinodal, 2005.

22 STRECK, 2005, p. 156.

${ }^{23}$ DREHER, 2005, p. 56. 
professoras que evitasse a dependência dos(as) docentes enviados esporadicamente pela Alemanha. Uma segunda, a necessidade de oferecer escolas com internatos que garantissem a continuação dos estudos após a conclusão da escola rural. Tais escolas, mais equipadas, deveriam localizar-se nos centros urbanos das regiões coloniais. Essas necessidades produziram uma profunda crise nas escolas comunitárias evangélico-luteranas. A crise destas escolas, no entanto, era decorrente de uma crise mais abrangente, a da escola pública. A situação educacional das colônias alemãs era menos precária, embora a presença educacional do Estado, na região, fosse menos significativa.

Em 1877, por exemplo, o Regulamento da Escola Normal da Província, aprovado pela Assembléia Legislativa, tornaria obrigatório o estudo de alemão para os futuros professores e professoras que desejassem lecionar nas áreas coloniais. No entanto, os esforços do governo provincial nunca foram suficientes. E, na falta de escolas públicas, a Igreja Luterana toma as iniciativas que lhe são possíveis. Em maio de 1897, a $\mathrm{XI}^{\mathrm{a}}$ Assembléia Geral do Sínodo Riograndense, por unanimidade, aprova a criação de um Seminário para a Formação de Professores, elegendo uma comissão escolar composta por cinco membros leigos e três pastores para implementá-lo.

O esforço e o investimento na formação de professores realizado pelas escolas comunitárias eram necessários, pois a única Escola Normal Pública mantida pelo governo provincial, criada em 1869, não conseguia formar professores em número suficiente sequer para a rede pública urbana da Província ${ }^{24}$. Além disso, a Lei no 771, de 4/05/1871, em seu artigo 22, previa que os estudantes da Escola Normal Públicadeveriam ter sua "conduta" moral verificada por "severa sindicância" e dominar as "principais doutrinas da religião do estado". Essa determinação legal impedia, na prática, o ingresso de pessoas evangélicas na docência, porque, simplesmente, não poderiam comprovar "boa conduta moral", já que seus pais não eram oficialmente casados pela Igreja Católica. Essa

\footnotetext{
${ }^{24}$ A formação de professores para a rede de escolas rurais só vai acontecer com o Plano de Estudos das Escolas Normais Rurais que formavam professores habilitados para atuar em regiões rurais ou cidades com menos de 7 mil habitantes, conforme o Decreto $\mathrm{n}^{\circ} 7.641$, de 28/12/1938.
} 
exigência político-ideológica foi extinta, em tese, na separação entre Estado e Igreja.

As escolas comunitárias eram parte integrante do meio cultural, específico das colônias, criadas pela imigração alemã, garantindo, por muitas décadas, um índice de comunidades superior ao verificado no contexto escolar da província do Rio Grande do Sul. Essa rede era, ao mesmo tempo, privada e pública. Privada por ser mantida pelos membros filiados à comunidade religiosa. No entanto, tinha o caráter de escola pública porque atendia a todas as crianças de origem alemã da comunidade local que, na prática, se confundia com a comunidade religiosa, dada as características impostas pelo Império Brasileiro à colonização alemã no sul do Brasil. Apesar disto, o isolamento cultural de grande parte das comunidades persistiu até a implementação do estado laico, cujo decreto da separação entre Estado e Igreja entrou em vigor no dia sete de janeiro de 1890.

\section{Considerações finais}

Em síntese, pode-se afirmar que a centralidade dos ideais da Reforma Protestante na herança luterana e na tradição comunitária, tem se expressado ao londo da historia da IECLB no Brasil pautada nos seguintes elementos de base:

$\left.1^{a}\right)$ Reciprocidade e Interação entre escola e comunidade: preocupação em atender aos interesses das comunidades locais e regionais e suas representações, principalmente, no que tange aos processos de formação e qualificaçãoprofissional.

$2^{a}$ ) Liberdade de expressão, autonomia de pensamento e igualdade de oportunidades: entendimento de que o/a estudante é uma pessoa livre e responsável para elaborar a sua própria compreensão de vida, que se manifesta nas formas de relacionar-se consigo mesmo, com outras pessoas e com o mundo que ocerca.

$3^{\text {a) }}$ Desenvolvimento integral do ser humano: profunda e íntima inter-relação entre as dimensões intelectual, moral, psicológica, religiosa, cultural social, econômica, política ebiológica. 
A preocupação dos imigrantes alemães em proporcionar aos filhos e filhas uma educação voltada para a consrução da vida coletiva e também individual tornou-se um marco na identidade das escolas comunitárias ligadas à tradição luterana ${ }^{25}$. Havia entre eles a firme convicção da importância da escola, criada por iniciativacomunitária e não somente como ação direta do Estado, para o desenvolvimento do processo educacional, além da presença de uma cultura européia do ensino realizado dentro do espaço institucional das igrejas e da influência de dois movimentos: ortodoxia e pietismo. É plausível afirmar que a comunitariedade foi o fator decisivo da motivação religiosa na educação luterana ${ }^{26}$.

Pode-se dizer assim, que a herança luterana ainda que não tenha formulado uma teoria pedagógica própria e autônoma, forneceu subsidios importantes para o estabelecimento de novas bases para que a educação brasileira fosse construída, sob a ótica da cidadania. Para Toledo

Tanto a defesa da escola quanto a crítica inseriam-senos contextos dos embates ideológicos e lutas políticas pela hegemonia cultural e religiosa na Europa do século XVI. Uma das grandes contribuições de Lutero no campo da educação reside no fato de ter defendido a universalização da alfabetização, que se tornou, depois dele, uma das

${ }^{25}$ De acordo com Dreher, 2005, p.72, “desde o século XVIII, a frequência à escola tornara-se obrigatória na Prússia, decisão que, aos poucos, foi sendo introduzida nos demais territórios alemães. Aos pastores e padresfoi confiada a função de inspetores escolares. A partir da iniciativa de Pestalozzi também foram criadasescolas normais para a formação de professores. Vivendo dessas tradições, desde cedo as comunidadesluteranas começaram a criar e manter escolas no Brasil."

${ }^{26}$ Segundo Dreher (1984) e Mendonça (1984), vale lembrar que o sistema educacional implantado no Brasil na segunda metade do século XIX pelos luteranos é bastante diferente daquele trazido pelo "protestantismo de missão", denominação protestante surgida no Brasil como conseqüência de atividades missionáriasdesenvolvidas desde os Estados Unidos da América do Norte pelos metodistas, presbiterianos, batistas, congregacionais, adventistas e anglicanos. Apesar da escola ser complemento natural da igreja, as razões desua implantação não são filantrópicas, mas doutrinais. Ao contrário do luterano, no protestantismo oriundo deatividade missionária predomina o magistério feminino. Ambos não pretendiam, assim como o catolicismo,apenas educar para a fé, mas dar também expressão aos "valores da vida crista", identificados aos valorespadrão dos diferentes países, por isto são valorizados temas como, por exemplo: liberdade, democracia,responsabilidade e êxito. 
mais importantes bandeiras desfraldadas e enfim conquistada pelos reformadores ${ }^{27}$.

Nesse sentido, um dos aspectos em destaque é considerar a preocupação com a formação docente precedendo às iniciativas destinadas à formação teológica, embora tenha nesta sua base. Ou seja, as práticas educativas e formativas ganham centralidade. Os(as) historiadores(as) do período inicial da imigração registram inúmeros exemplos de pais que ensinavam os filhos e as filhas em casa, admitindo neste ensino, também, os filhos e as filhas de vizinhos, numa espécie de ensaio primitivo para o que viria a constituir-se na rede de escolas comunitárias evangélico-luteranas.

Desde o início, o maior problema enfrentado pelas comunidades alemãs foi a formação e a capacitação de professores e professoras. Devido às precárias condições de sua implantação inicial, foi necessário admitir pessoas que, na maioria das vezes, não dispunham de qualificação profissional formal, mas que exerciam expressiva liderança intelectual nas comunidades. No decorrer dos anos, esse fato geraria, de forma concomitante, tanto prejuízos, quanto vantagens ao ensino. Os prejuízos, pela fragilidade de formação dos professores e das professoras e as vantagens, pelo compromisso de solidariedade comunitária dos professores e professoras com seus estudantes.

Outro aspecto importante na análise histórica, de acordo com Dreher $^{28}$, sobre o perfil que foi sendo implementado na relação estabelecida entre as comunidades e as escolas é a presença de imigrantes assumindo as funções de pastor-colono e mestre-escola, fato esse que se mantêm, de maneira expressiva, até a Segunda Guerra Mundial.

Sobre esse assunto, há de se considerar que havia, por parte desses imigrantes que chegaram ao Brasil, um forte sentimento de preocupação aliado ao compromisso permanente com a causa educacional. Afora isso, evidencia-se, nessas funções exercidas, que o processo de clericalização foi, em parte, postergado.

${ }^{27}$ TOLEDO, Cézar de Alencar Arnaut de. A questão da educação na obra de Martinho Lutero. Acta Scientiarum, Maringá, 21(1), 1999, p. 130.

${ }^{28}$ DREHER, Martin N. Igreja e germanidade: estudo crítico da história da Igreja Evangélica de Confissão Luterana no Brasil. São Leopoldo: Sinodal, 1984. 
Com o desenvolvimento sócio-econômico das regiões de colonização alemã, as pequenas escolas, destinadas à alfabetização, ao ensino da religião e à manutenção da cultura, também cresceram. Segundo Streck ${ }^{29}$, "Dentre as atividades educativas deve ser sublinhado o papel do ensino confirmatório. [...] este é o lugar onde no fundo se define a questão teológica e pedagógica da Igreja, uma vez que, com raras exceções, todos os membros da IECLB passaram e ainda passam porele".

Nas últimas décadas do século XIX e nas duas primeiras do século $\mathrm{XX}$, os intelectuais da comunidade teuto-brasileira consideravam o Brasil como o seu "país" e a cultura alemã como uma das muitas existentes no território nacional. Havia, pois, a premente preocupação de formar professores e professoras advindos de seu próprio meio cultural. Assim, desde o início, as escolas comunitárias pretenderam dar expressão à cultura de seus estudantes e de promovê-la entre esses próprios pares, como condição para preservar, aperfeiçoar e contribuir com o progresso das ciências e da civilidade brasileiras.

Um salutar exemplo dessa preocupação aconteceu em São Leopoldo, RS. O Pastor Dr. Wilhelm Rotermund, de sólida formação humanística, obtida em Universidades alemãs, enfrenta o problema educacional de forma inusitada e desafiadora. Em 5 de abril de 1887, cria em sua própria casa uma escola com internato, destinada à formação de professores. Chamou-se de "Escola Nova" e sua primeira turma reuniu 19 estudantes.

A contribuição pedagógica de Wilhelm Rotermund extrapola o ambiente das comunidades evangélicas. O seu livro Sylabario ${ }^{30}$, um manual escrito em alemão para ensinar português, publicado em sua Editora, é adotado pelo governo provincial em 4 de maio de 1878, para uso nas escolas das colônias. Merece destaque, ainda, outros trabalhos, de natureza didático-pedagógica, de Wilhelm Rotermund, como a Gramática para Estudo da Língua Portuguesa ${ }^{31}$ e a Orthopedia da Língua

${ }^{29}$ STRECK, 1995, p. 28.

${ }^{30}$ ROTERMUND, Wilhelm. Fibel für deutsche Schulen in Brasilien. Neubearbeitet Von R. Heuer. $5^{\text {a }}$ ed. SãoLeopoldo: Rotermund, 1927. A primeira edição data do início do século.

${ }^{31}$ ROTERMUND, Wilhelm. Vollständige Grammatik der portugiesischen Sprache in Regeln und Übungsstücken. $7^{\text {a }}$ ed., São Leopoldo: Rotermund, 1925. A primeira edição é de 1897 e em seu prefácio Rotermund escreve: "Em meu entender, é tarefa 
Portuguesa $^{32}$. Theodor Grimm publicou Conhecimento do Estado do Rio Grande do Sul ${ }^{33}$ e Bruno Stysinski produziu o Esboço da História do Brasil $^{34}$. Aliás, a produção de material didático é expressiva nas escolas comunitárias luternas.

A elaboração dessas publicações estava fundamentada no método intuitivo e tinha um grande interesse em apresentar traços da identidade brasileira; hoje talvez o designássemos de construtivista. A preocupação constante com a formação contínua de adultos, tendo em vista a cidadania e o preparo para ela fez de Rotermund \& Co, em São Leopoldo, RS, a maior editora de material didático da América do Sul, em sua época.

\section{Referências}

ALTMANN, Friedhold. A roda: memórias de um professor. São Leopoldo: Sinodal, 1991.

ALTMANN, W. Lutero e libertação. São Paulo: Ática, 1994.

ALTMANN, Walter. El pluralismo religioso como reto al ecumenismo y a la misión en América Latina. Alternativas, Manágua, v. 8, nº 20/21, p. 185-198, 2001.

ALVES, Ruben. Protestantismo e repressão. São Paulo: Ática, 1979.

BAESKE, Albérico. Educação para a liberdade: uma visão luterana. In: Estudos Teológicos. São Leopoldo: Sinodal, ano 25, nº 1, 1985, p. 7-12.

BARBOSA, Luciane Muniz Ribeiro. As concepções educacionais de Martinho Lutero. Educação e Pesquisa, São Paulo, v. 33, nº 1, p. 163-183, jan./abr. 2007.

da escola alemã introduzir as crianças, que se deparam coma língua portuguesa enquanto língua viva e que a aprendem a usar com facilidade, em sua brilhante estrutura,fornecer-lhes percepção de sua estrutura lógica por meio de regras e de exercícios planejados e capacitá-las autilizar corretamente esta bela língua, a qual infelizmente é muitas vezes mal falada e escrita" (p. III).

32 ROTERMUND, Wilhelm. Orthopedia da Lingua Portuguesa. 10a ed., São Leopoldo: Rotermund, 1908. A Orthopedia tem como mote "falar, escrever e ler deve juntar-se".

${ }^{33}$ GRIMM, Theodor. Heimatkunde des States Rio Grande do Sul. Santa Cruz: Stutzr \& Hermsdorf, 1891. Olema do livro é: "para amar nossa querência é necessário conhecê-la".

${ }^{34}$ STYSINSKI, Bruno. Grundriss der Geschichte Brasiliens. São Leopoldo: Rotermund, s.d. 
COSTA, Miguel Ângelo S. da; DREHER, M. N.; CARVALHO, Enildo de M. (Org.). Explorando possibilidades. Experiências e interdependências sociais entre imigrantes alemães, seus descendentes e outros mais no Brasil Meridional. 01. ed. Santa Cruz do Sul: EDUNISC, 2009.

DREHER, M. N. Breve história do ensino privado gaúcho. 01. ed. São Leopoldo/RS: Oikos, 2008.

DREHER, Martin N. (org.). Populações Rio-Grandenses e modelos de igreja. São Leopoldo e Porto Alegre: Sinodal e Edições EST, 1998.

DREHER, Martin N. A igreja latino-americana no contexto mundial. São Leopoldo: Sinodal, 1999.

DREHER, Martin N. História do Povo Luterano. São Leopoldo: Sinodal, 2005.

DREHER, Martin N. Igreja e germanidade: estudo crítico da história da Igreja Evangélica de Confissão Luterana no Brasil. São Leopoldo: Sinodal, 1984.

DROSTE, Rolf(org.). Instituto Pré-Teológico. Uma escola singular. São Leopoldo: Sinodal, 1997.

GRÜTZMANN, I.; DREHER, M. N.; FELDENS, J. A. Imigração Alemã no Rio Grande do Sul. Recortes. 01. ed. São Leopoldo: Oikos, 2008.

GOLDMEYER, Marguirit; Manfredo Carlos; MALSCHITZKY, Gustavo (org.). Luteranismo e Educação: Reflexões. 01. ed. São Leopoldo: Sinodal, 2006.

KREUTZ, Lúcio. Material didático e currículo na escola teuto-brasileira do Rio Grande do Sul. São Leopoldo: UNISINOS, 1994.

LÉONARD, Emile G. O protestantismo brasileiro. São Paulo: ASTE, 1963.

LOURO, Guacira Lopes. História, Educação e Sociedade no Rio Grande do Sul. Porto Alegre: Educação e Realidade Edições, 1986.

LUTERO, Martinho. Aos Conselhos de todas as cidades da Alemanha para que criem e mantenham escolas cristãs. Obras Selecionadas. Vol. 4.e 7 Porto Alegre, São Leopoldo: Concórdia, Sinodal, 1995.

LUTERO, Martinho. Educação e Reforma. São Leopoldo: Sinodal; Porto Alegre: Concórdia, 2000.

MENDONÇA, Antonio Gouvea e VELASQUES, $\mathrm{F}^{\mathrm{o}}$, Prócoro. Introdução ao protestantismo no Brasil. São Paulo: Loyola, 1990. 
MEYER, Dagmar Elisabeth Estermann. Identidades traduzidas: cultura e docência teuto- brasileiro-evangélica no Rio Grande do Sul. São Leopoldo/Santa Cruz do Sul: Sinodal/EDUNISC, 2000.

MÜLLER, Reinhart. A transferência da V Assembléia geral da Federação Luterana Mundial de Porto Alegre para Evian/França. In: FISCHER, Joaquim. Ensaios luteranos: dos primórdios aos tempos atuais do luteranismo no Brasil. Trad. Walter O. Schlupp. São Leopoldo: Sinodal, 1986.

NOGUEIRA, S. V.; RODRIGUES, Osvaldino Marra. A herança luterana e a tradição comunitária no Instituto Ecumênico de Pós-Graduação (IEPG): interfaces da produção científica em Teologia. 01. ed. Canoas: Salles Editora, 2007.

PAIVA, César. Escolas de língua alemã no Rio Grande do Sul e a política de nacionalização. Educação e Sociedade. Campinas: Papirus/ CEDES, ano 9, n 26, abril de 1987, p. 5-28.

SANTOS, Boaventura de Sousa. A crítica da razão indolente: contra o desperdício da experiência. São Paulo: Cortez, 2000.

SCHENEIDER, Regina Portella. A instrução pública no Rio Grande do Sul (1770-1889). Porto Alegre: Editora da Universidade-UFRGS/ EST Edições, 1992.

STRECK, Danilo Romeu (org.). Educação e Igrejas no Brasil: um ensaio ecumênico. São Leopoldo: CELADEC, 1995.

STRECK, Gisela I.W. Escola comunitária: fundamentos e identidade. São Leopoldo: Editora Sinodal, 2005.

TOLEDO, Cézar de Alencar Arnaut de. A questão da educação na obra de Martinho Lutero. Acta Scientiarum, Maringá, 21(1), 1999, p. 129-135.

WEBER, M. A ética protestante e o espírito do Capitalismo. 13 ed. São Paulo: Pioneira, 1999.

Submetido em: 17/05/2016

Aceito em: 22/06/2016 